\title{
STABILITY AND CONTROL ASPECTS OF MICRO-GRID ARCHITECTURES OF WIND POWER SYSTEM
}

\author{
Muhammad Aamir Khan \\ Department of Electrical \\ Engineering, \\ Islamia University of Bahawalpur, \\ Pakistan \\ Sajid Mehmood \\ Department of Elctronics \\ Engineering, \\ Islamia University of Bahawalpur, \\ Pakistan
}

\author{
Huzaifa Zahid* \\ Department of Electrical \\ Engineering, \\ University of Lahore, \\ Pakistan
}

Muhammad Zulqarnain

Department of Electrical Engineering,

Islamia University of Bahawalpur, Pakistan

\author{
Muhammad Faheem Anwar \\ Department of Electrical \\ Engineering, \\ Islamia University of Bahawalpur, \\ Pakistan \\ Muhammad Naveed \\ Department of Electrical \\ Engineering, \\ Islamia University of Bahawalpur, \\ Pakistan
}

\begin{abstract}
Voltage unstability nowadays is a serious problem, Present day electric power utilities are confronting numerous difficulties because of regularly expanding multifaceted nature in their task and structure. One issue that got wide consideration is voltage instability. One of the significant reasons for voltage instability in the power framework is with its receptive power limit. It can cause different damages to our electrical appliances, and therefore the approach used in this research is for the benefit for these dangerous phenomenon. In this research Voltage control single phase STATCOM using different sources such as Photovoltaic Cell, DC generator, battery and WAPDA used, in such a way to have a backup voltage source to have an untriptable supply, in case of less than 9 $V$ the relay converter used the DC generator as back end source. It is a controller based system, controller on the basis of voltages changes the source to $\mathrm{PV}$ to $\mathrm{DC}$ and $\mathrm{DC}$ generator to Battery depends upon the voltages. Inverter is used which take input of $12 \mathrm{~V}$ that are controlled by relay in case of $P V$ it is stabilized by buck converter. $1 \mathrm{kVA}$ Transformer then sets the voltage to $230 \mathrm{~V}$ single phase, STATCOM is used after transformer to set the voltage at $230 \mathrm{~V}$ Power and Voltage monitoring system is used to check power and voltages at every point.
\end{abstract}

Keywords-PID, STATCOM, Microgrid

\section{INTRODUCTION}

The serious issue in power system is its instability. Power system soundness is the ability of the system to keep up a working harmony point in the wake of being exposed to an unsettling influence for given starting working conditions. [1] Reasonable gadgets like Automatic Voltage Regulators (AVR) are utilized for the guideline of created voltage. AVR's regularly keep up the generator voltage greatness at a predetermined dimension. AVRs are widely utilized on the dynamic or relentless state steadiness of the power system as low frequencies motions continue for a significant lot and may influence the capacity of power exchange. Electrical power is ascending at an exceptionally higher rate due to fast mechanical advancement. So as to fulfill the interest, power transmission must be raised alongside the current offices. Consequently it is fundamental to think for the power stream control. The power system ought to be adaptable to adjust to any fleeting changes in system conditions. In an AC power system, there must be a harmony between the produced power and varieties in burden request while keeping the system recurrence and voltage levels as steady. On the off chance that age isn't adequate, the voltage and recurrence drop, and the heap diminishes to adjust the short misfortunes in transmission.[2],[3],[4] In any case, there are just a couple of percent edges for such a self-guideline. Subsequently the system is crumpled. Generator excitation controller typically improves solidness for littler blames however not appropriate for bigger flaws that happen close to generator terminals. [5] Voltage instability because of "visibility" of the possibilities was the fundamental explanations behind the ongoing 


\section{International Journal of Engineering Applied Sciences and Technology, 2021 \\ Vol. 6, Issue 4, ISSN No. 2455-2143, Pages 137-144 \\ Published Online August 2021 in IJEAST (http://www.ijeast.com)}

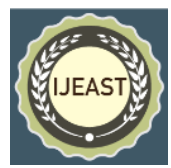

In this proposed system four voltage sources are separately working as a voltage, but each voltage source is a backup for the other source. It has been used four sources, photovoltaic cell produces $\mathrm{V}$ of at least 12 to $17 \mathrm{~V}$, buck converter is used to stabilize this AC voltage into $12 \mathrm{~V}$ and pass it to relay, if in case, darker region photovoltaic cell will not produce any voltage the system will have to shift to the DC generator, which is converting mechanical energy into electrical voltage, it can be a wind power source, relay is used to shift the backup system at the end inverter is used to invert voltage to the transformer and then to STATCOM because it deals which DC voltage after relay switch is used to stabilize the load, LC is used as a Load. Voltage instability is the reason for the framework voltage breakdown, in which the power framework voltage rots to a dimension, from which guide, it is unfit to recuperate. Voltage breakdown may prompt incomplete or full power intrusion in the framework. Giving sufficient receptive power support at the fitting area tackles voltage instability issues. Power quality is a noteworthy issue in the circulation framework. Here a STATCOM is utilized as a FACT gadget which can repay responsive power. STATCOM is three stage voltage source converter used to repay voltage and make the framework stable by retaining and producing receptive power. Main contributions towards this research are:

- Voltage control single phase STATCOM using different sources such as PV, DC generator, battery and WAPDA.

- In this project in case of less than $9 \mathrm{~V}$ the relay converter used the DC generator as back end source.

- It is a controller based system, controller on the basis of voltages changes the source to PV to DC and DC generator to Battery depends upon the voltages.

- Inverter is used which take input of $12 \mathrm{~V}$ that are controlled by relay in case of PV it is stabilized by buck converter. $1 \mathrm{kVA}$ Transformer then sets the voltage to $230 \mathrm{~V}$ single phase.

- It has been used STATCOM after transformer to set the voltage at $230 \mathrm{~V}$.

- Power and Voltage monitoring system is used to check power and voltages at every point.

- LC load used, not have used Resistance due to high voltage, it can cause fluctuation in voltage.

It has been used inductor capacitance as a load in the end of relay for less fluctuation, and our approach of using buck inverter is unique because buck converter stabilized the voltage to $12 \mathrm{~V}$ which transferred to next single phase in inverter

Power quality is defined of electrical limits that enable the bit of hardware to work in its proposed way without critical loss of execution. Receptive power can't be transmitted crosswise over huge power edge even with considerable voltage size angle. Responsive power ought to be produced near the purpose of utilization. There can be make a few motivations to limit receptive power exchanges. [6]

Voltage breakdown wonders in power frameworks are caused because of voltage instability when it is stacked past Maximum Loading Point (MLP) [1]. A few reports on PV curves are made with seat hub bifurcations and voltage breakdown issues [2]. In light of bifurcation hypothesis, the calculation of the breakdown point is done through direct or continuation techniques [3]. These procedures include the distinguishing proof of the framework harmony focuses or voltage breakdown focuses where the related power flow Jacobian ends up solitary [4], [5]. STATCOM is one of the FACTS hardware which utilizes the control gadgets to control the power stream and improve the passing stability in the power frameworks. It controls the recurrence in the side stations as it controls the responsive control infusion or retaining it from the electrical framework. At the point when the frameworks' recurrence is low the STATCOM infuses capacitive power. What's more, when the framework recurrence is high at that point it ingests the inductive power. Figure (1) speaks to a schematic graph for the STATCOM mixes where components from power gadgets can be us like IBGTs or IGCTs. The STATCOM fundamentally comprises of two sections, the power and control.[15], [16]

$$
Q=\frac{V 1(V 1-V 2)}{X}
$$

The power circuit comprises of Transistor Scaffold (6 transistors) and three loops functions as a recurrence increaser, and a capacitor with high stockpiling limit with respect to putting away and infusion the capacitive power. The scaffold control circuit comprises of a gathering controlling the beat width and review and estimating current and recurrence gathering. The current is constrained by inward circuit that transforming it. The external circuit estimates the recurrence and creates beats so it can move in the power capacitive in the three stages. This power at times it is being put away what's more, in different cases it is infused amid next to no occasions concurring the net recurrence wave and makes the current wave as the recurrence wave, and after that the power factor is improved to accomplish the nearly unit esteem. [17], [18]

These applications shift as per the main and investigation framework. It very well may be utilized to overlook the fittings in the general net what's more, improve the power parameter where it can control the framework and work as the framework prerequisites. In other words, it works in putting away and infusing the current as per the oppressed mistake. This framework can be worked as branch dynamic channel works legitimately with the matrix. Likewise, it tends to be utilized as an AC/DC converter works at unit control factor [12, 13]. Stream between the sources V1 and V2. V1 speaks to the controlled framework recurrence while V2 the came about recurrence in VSC. In consistent state case, the came about V2 recurrence from VSC is in a similar stage with V1, and the point rises to zero. The power stream relies upon the recurrence, on the off chance that $\mathrm{V} 1>\mathrm{V} 2$, at that point the receptive power stream (Q) streams fromV1 toV2 while the STATCOM ingests the receptive power.

The capacitor is associated on the immediate current side (DC) of the VSC and goes about as ceaseless recurrence source. In consistent state case, V2 must have a little stage distinction 


\section{International Journal of Engineering Applied Sciences and Technology, 2021 \\ Vol. 6, Issue 4, ISSN No. 2455-2143, Pages 137-144 \\ Published Online August 2021 in IJEAST (http://www.ijeast.com)}

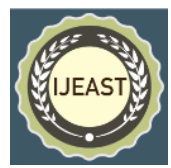

from V1 to repay the changing misuse of the VSC and save the capacitor charged. The capacitors, as a rule, associated with the steady speed STATCOM turbines to improve the framework's recurrence as it is the wellspring of receptive power. Fixed release capacitors can improve stressed stability of the framework yet isn't delicate to recurrence changes. [15], [16] Consistent capacitor can't go about as a solitary source to adjust for responsive power. One of the principle advantages of utilizing STATCOM is that the repaid control isn't reliant on the dimension of recurrence in the contact point, which implies that the remunerated current does not decrease. The breeze ranch efficiency differs just as the all-out burden all the day. Repaying the responsive power is required to protect the recurrence levels enduring in the electrical framework.

The unbalance of the receptive power can influence truly on the matrix recurrence. This impact can be decreased by utilizing STATCOM as it can contribute in the necessities of low voltage amid default or aggravation event in the network $[15,16]$.

Synchronous voltage source with least and most extreme voltage size points of confinement is implied as STATCOM. The transport at which STATCOM is associated is alluded as PV, which may change to PQ transport in the occasions of cutoff being violet. Portrayal of STATCOM is as appeared in Fig. By supplanting banks of shunt capacitor, it is utilized for the voltage pay at the beneficiary end of a transmission lines.

A few papers about Microgrid, for example, [7], have been explored by the creator and the idea of the Power Sub Grid was created. It has been seen that the Microgrid has interconnection issues and limit requirements [8]. With the improvement of the Vitality Storage (ES) System, Distributed Generation (DG) is certainly not an unquestionable requirement for the Microgrid. Moreover, there is no need the purported Power Electronic Interface (PEI) between the Microgrid and the primary power framework if the DG is outfitted with suitable control. In this way, the idea of the Power Sub Grid, is increasingly material to the power lattice, and can be connected for the ES framework, DG framework, and any kind of burdens inside the power framework. Staggered Converter (MLC) numerous papers have been distributed about Multi-level converters (MLC). A couple of illustrative major ones are [3], [4], [6], [9]. Exceptionally nitty gritty delineation, tweak, reenactment, and assessment of the staggered converter is given in [7]. Together with [4], they give great information about the balance of the staggered converter, which gives the voltage guideline and orchestrates the sinusoidal waveform. Their computations about the loss of exchanging and conduction are exceptionally great.

From these works, the impediment of the staggered converter can be effectively observed with the yield voltage control. There are numerous approaches to control the abundancy of the yield voltage. The common technique with the MLC is still with PWM adjustment, and exchanging misfortune together with the Electromagnetic Interference (EMI) are principle issues with functional uses of the MLC. Along these lines, finding another topology with high power converter is important. Reference [6], the principal formal production portraying capacitor voltage blend based staggered converter, brought up its potential applications. The main capacitor voltage combination based staggered converter is the Diode-Clamp staggered converter, which comprises of m-1 capacitors on the DC transport, and delivers $m$ dimensions of the stage voltage. The second one is the staggered converter utilizing flying capacitors, which are charge siphons in the circuit to increment the DC source voltage. Flying capacitors give greater adaptability of blends for voltage union. The last one is the fell inverters with independent DC sources. This paper moreover represented focal points and drawbacks of these staggered converters, and brought up their potential applications including responsive power remuneration. Reference [9] presents an instructional exercise on staggered converter innovation, which empowers power electronic advancements for high power applications

Human exercises, the most imperative of which are the consuming of non-renewable energy sources, for example, coal, oil and gas, cause serious harm to the earth [1]. Environmental change has moved toward becoming a noteworthy issue for the youthful and the huge and one of the most vital issues influencing the national development of any nation [2]. The utilization of non-renewable energy sources has multiplied as of late because of the expansion in populace over the globe [3]. The vacillation of oil costs caused monetary fiascos both for delivering and bringing in nations [4].

The world needs to swing to spotless, sustainable and earth well-disposed options, for example, sun based, STATCOM what's more, geothermal vitality [5, 6]. Sun based vitality has gone a long way and sun based power plants are presently accessible in many parts of the world. They can likewise be produced at the house level also, are associated with the system or inconsequential $[7,8]$.

The utilization of STATCOM vitality in electrical frameworks has been expanded in everywhere throughout the world in the ongoing years. Numerous new issues have showed up which built up an interest for treating these issues identified with making the electrical framework stable. This framework normally has variable vitality assets as steam plants, gas, nuclear, pressure driven, photovoltaic and STATCOM vitality [9].

Before, the breeze vitality share in the power framework was speaking to a minor part. In any case, the expanded also, persistent association of gigantic breeze homesteads to the power lattice (which wasn't speaking to any dread in the past). As of late, the association of STATCOM homesteads to the framework assumes a noteworthy job in accomplishing the required power for the oppressed burden incorporating the unsettling influence conditions in the lattice [10].

The association prerequisites with the lattice are norms that are being enacted by controlling organizations to control the homogenous work between the breeze ranches and the electrical lattices. These benchmarks change from one nation to another and the breeze ranches frameworks need to deal with these necessities to have the capacity to interface with the matrix [11]. 


\section{International Journal of Engineering Applied Sciences and Technology, 2021 \\ Vol. 6, Issue 4, ISSN No. 2455-2143, Pages 137-144 \\ Published Online August 2021 in IJEAST (http://www.ijeast.com)}

One of the essential issues identified with interfacing the STATCOM ranch to the network is the stability of the voltage of electrical framework when a flaw or unsettling influence occurs in the matrix. At this stage, the electrical framework will be not ready to fulfill the heap necessities because of voltage decrease exists due to these deficiencies, substantial fellow conditions, or the abrupt stop of one of the producing units. The static synchronous repaying framework (STATCOM) is utilized broadly in electrical frameworks due to its capacity to control the versatile control stream that helps the matrix in safeguarding stability in the characteristic task or in fouling cases or other exchanging conditions [12].

The explanation behind utilizing STATCOM in the breeze ranches is its capacity to give a supporting voltage to the bar in the event that of voltage bar's decrease or retaining the extra responsive power from the electrical framework because of burdens decrease and save the voltage at it ostensible esteem.

The vast majority of the breeze generators introduced in the past were inductive generators which expend receptive power from the framework even in normal task conditions. In the last a long time, high quantities of STATCOM turbines with variable paces with multiplied bolstered enlistment generators. In the typical condition, the generator works with power factor close one. The inductive generator may require responsive power amid its looking for certain unsettling influences as three stage deficiency close to the breeze ranch. For fulfilling the framework necessity ceaselessly the breeze turbines amid the flaw presence, the ranches with receptive generators needs to utilize a capacitors gathering to present a supporting receptive power for the framework in its ordinary and unusual activity. STATCOM is described by IEEE as a self-commutated trading power converter gave from a fitting electric essentialness source and attempted to make a great deal of portable multiphase voltage, which may be coupled to an AC power structure to trade unreservedly controllable certifiable and responsive power.

Power electronic based hardware, for example, FACTS controllers, with their capacity to quickly react to framework occasions, increment control exchange confines, and improve the nature of intensity conveyed, comprise a standout amongst the most-encouraging specialized progressions to address the new working difficulties being exhibited today. The STATCOM is three stage shunt associated power hardware based gadget. It is associated close the heap at the conveyance framework. It is additionally a one sort of the voltage-source converter, which changes over a DC input voltage into AC yield voltage so as to remunerate the dynamic and receptive power required by the framework. The STATCOM for the most part comprises of DC voltage source behind self-commutated inverters utilizing IGBT what's more, coupling transformer. A three stage IGBT based current controlled voltage source inverter with a dc transport capacitor is utilized as a STATCOM. STATCOM improves supply power factor, give load adjusting and improve load terminal voltage. STATCOM limits the short out current, improves the framework transient stability limit and builds the heap capacity of the framework. STATCOM controller is exceptionally successful in improving the power quality at the dispersion level by making the voltage stable. A voltage Source converter is associated with transport through three stage transformer. A voltage source converter is a power hardware gadget, which can produce sinusoidal voltage with required size recurrence and stage edge. A $10000 \mu \mathrm{F}$ capacitor is utilized as a dc voltage hotspot for the inverter

\section{PROPOSED AlgORITHM}

It has been used MATLAB/SIMULINK in our simulations to show the responses of our project. Voltage instability because of "visibility" of the possibilities was the fundamental explanations behind the ongoing

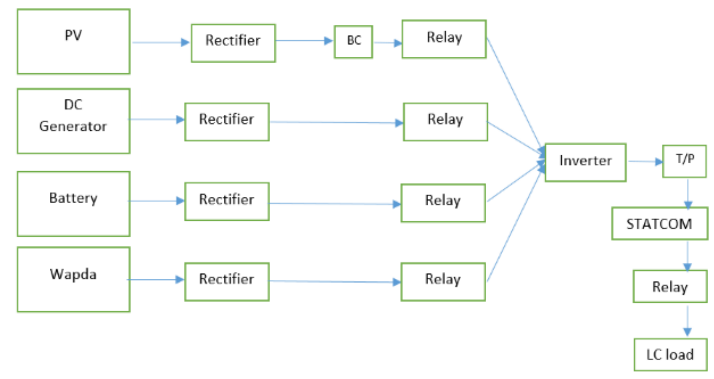

Figure 1 Project block Diagram

Four voltage sources are separately working as a voltage, but each voltage source is a backup for the other source. It has been used four sources, photovoltaic cell produces $\mathrm{V}$ of at least 12 to $17 \mathrm{~V}$, buck converter is used to stabilize this AC voltage into 12 $\mathrm{V}$ and pass it to relay, if in case, darker region phot voltaic cell will not produce any voltage the system will have to shift to the DC generator, which is converting mechanical energy into electrical voltage, it can be a wind power source, relay is used to shift the backup system at the end inverter is used to invert voltage to the transformer and then to STATCOM because it deals which DC voltage after relay switch is used to stabilize the load, LC is used as a Load.

Voltage instability is the reason for the framework voltage breakdown, in which the power framework voltage rots to a dimension, from which guide, it is unfit to recuperate. Voltage breakdown may prompt incomplete or full power intrusion in the framework. Giving sufficient receptive power support at the fitting area tackles voltage instability issues. Power quality is a noteworthy issue in the circulation framework. Here a STATCOM is utilized as a FACT gadget which can repay responsive power. STATCOM is three stage voltage source converter used to repay voltage and make the framework stable by retaining and producing receptive power. Voltage control single phase STATCOM using different sources such as PV, DC generator, battery and WAPDA. In this project in case of less than $9 \mathrm{~V}$ the relay converter used the DC generator as back end source. It is a controller based system, controller on the basis of voltages changes the source to PV to DC and DC generator to Battery depends upon the voltages. 


\section{International Journal of Engineering Applied Sciences and Technology, 2021 \\ Vol. 6, Issue 4, ISSN No. 2455-2143, Pages 137-144 \\ Published Online August 2021 in IJEAST (http://www.ijeast.com)}

Inverter is used which take input of $12 \mathrm{~V}$ that are controlled by relay in case of PV it is stabilized by buck converter. 1kVA Transformer then sets the voltage to $230 \mathrm{~V}$ single phase.

It has been used STATCOM after transformer to set the voltage at $230 \mathrm{~V}$. Power and Voltage monitoring system is used to check power and voltages at every point. LC load used, not have used Resistance due to high voltage, it can cause fluctuation in voltage.

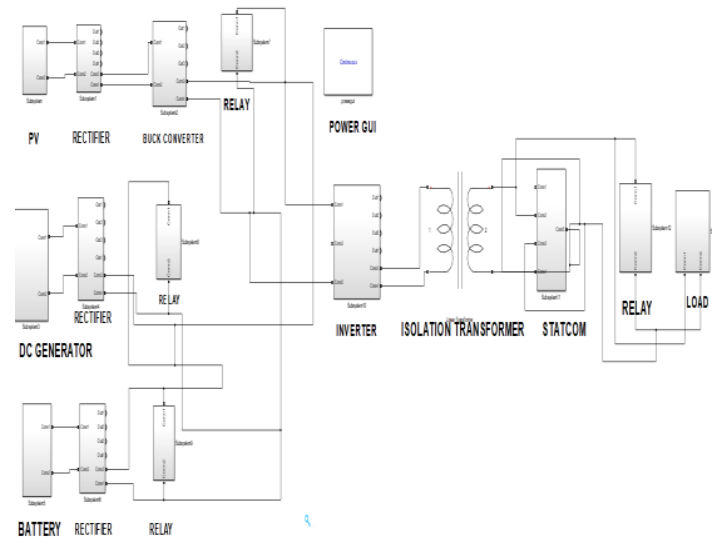

Figure 2 Simulink Model of Project

Inverter has the opposite functionality to change DC into AC current It has been used is to generate $\mathrm{AC}$ at the end with stable voltages in order to pass it to the transformer.

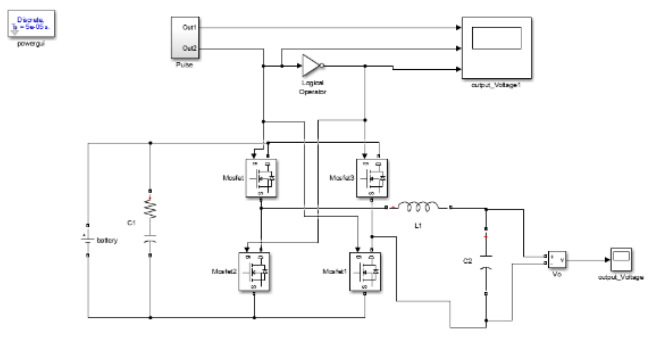

Figure 3 Simulink Model of Inverter

Rectifier is also used to convert AC current to DC, by it straights the direction of current into direct. It will be used before relays as relays use DC current to operate.

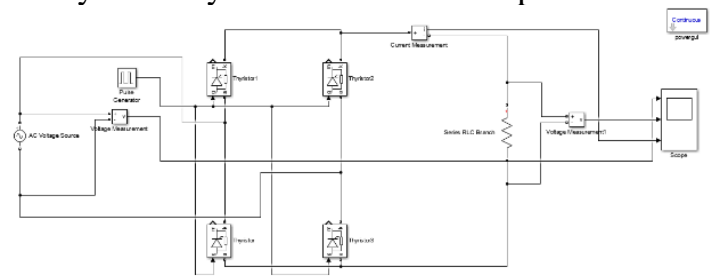

Figure 4 Simulink Model of Rectifier

Photovoltaic produce AC current as a result of intensity of light, as a result Sine wave produced by SPVM is then transferred to the rectifier to produce DC half wave rectified output and then inverter take it as an input to generate AC voltage to pass it out to STATCOM.

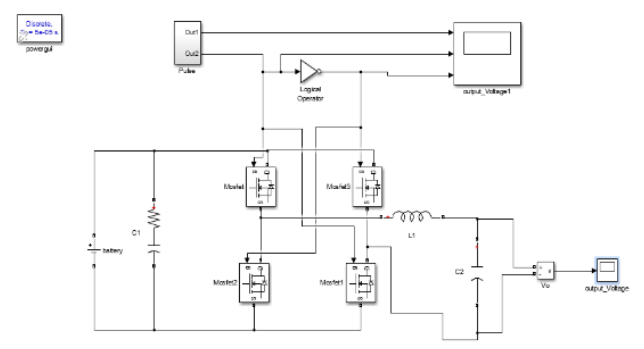

Figure 5 Sine wave Inverter Simulink Model

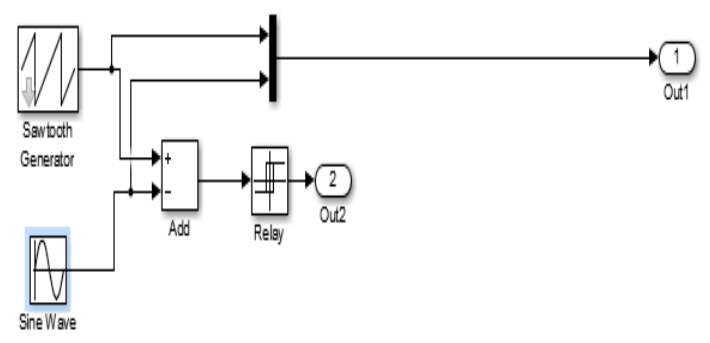

Figure 6 Pulse CCT Simulink Model

Saw tooth generator is used a pulse generator here to adds with a sinusoidal wave and an adder giving the sine wave in the output 1 and a relay converted output 2 .

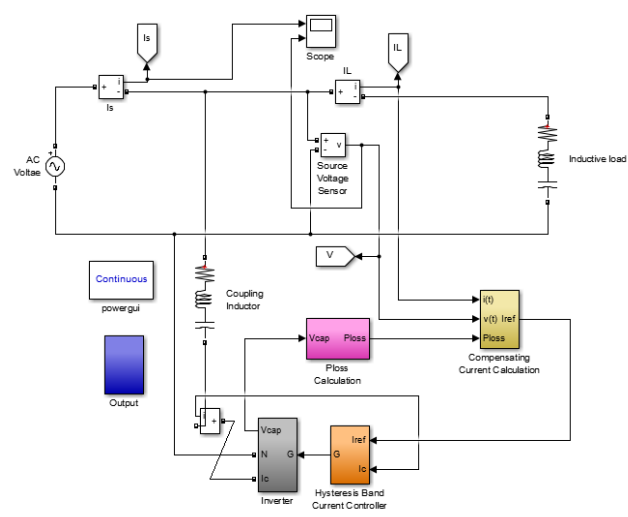

Figure 7 . STATCOM Simulink Diagram 
International Journal of Engineering Applied Sciences and Technology, 2021

Vol. 6, Issue 4, ISSN No. 2455-2143, Pages 137-144

Published Online August 2021 in IJEAST (http://www.ijeast.com)

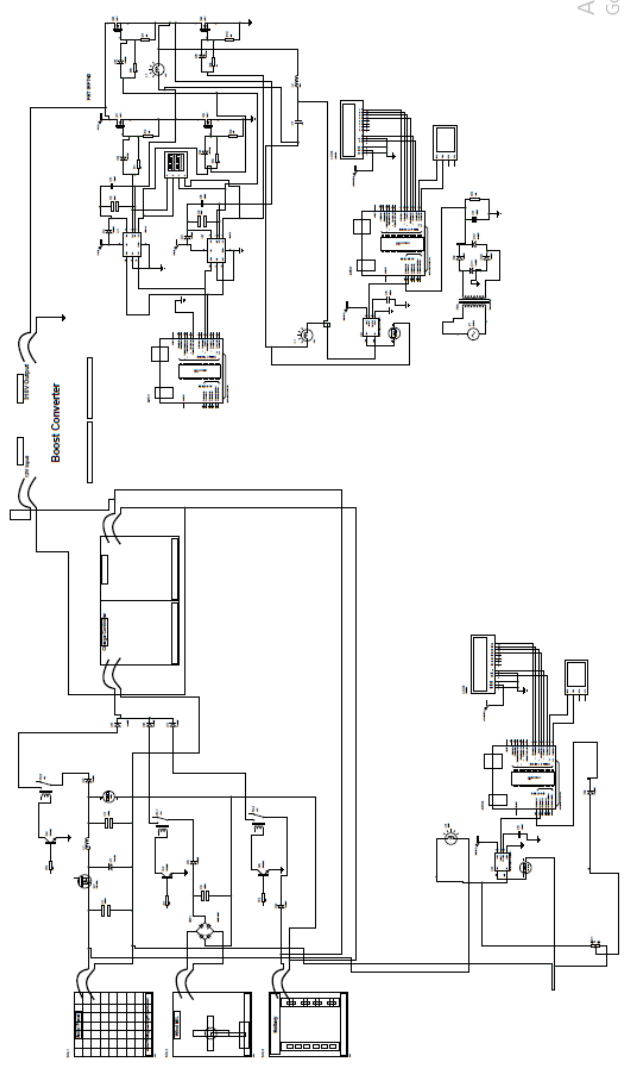

Figure 8 Complete Layout of Proposed Work

In this part, it is discussed the way used to execute this project on software. In this section it is discussed going to produce a voltage stability and instability issue discussed and to explain it by utilizing STATCOM system. MATLAB/Simulink programming has been utilized and $11 \mathrm{kV}$ appropriation conspire has been executing in MATLAB/Simulink programming. Most importantly, the dispersion framework with four feeders has been structure. At that point to make voltage lists, three stage deficiency has been connected at one of the feeder. From that point onward, run the recreation between 0 until 1 second to see the voltage droops waveform. At that point, to propel the voltage unstability, STATCOM gadget will be placed in into the circulation framework. STATCOM comprises of controller structure, Voltage Source Converter (VSC) and vitality stockpiling circuit. A while later, the wave shape from the degree can be examined to watch the either the voltage unstability had shown signs of improvement or not using STATCOM

\section{EXPERIMENTAL RESULTS}

Photovoltaic cell generating the voltage of AC about 14 to 17 $\mathrm{V}$ in the input which is stabilized by the buck converter to $12 \mathrm{~V}$ as a standard voltage used in this project.
Input pulses of saw tooth generator and sinusoidal waves are added as a result to create two different outputs. An adder is added in the output of the two generator having the two outputs.

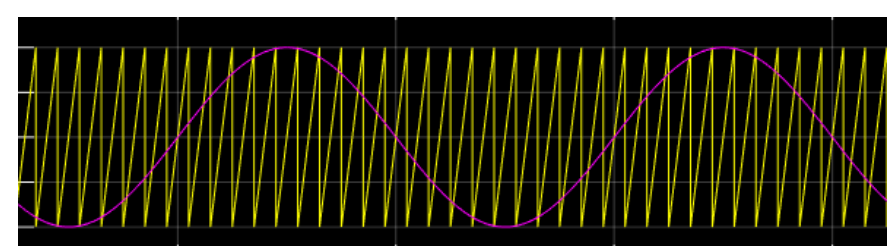

Figure 9 Output of Buck Converter

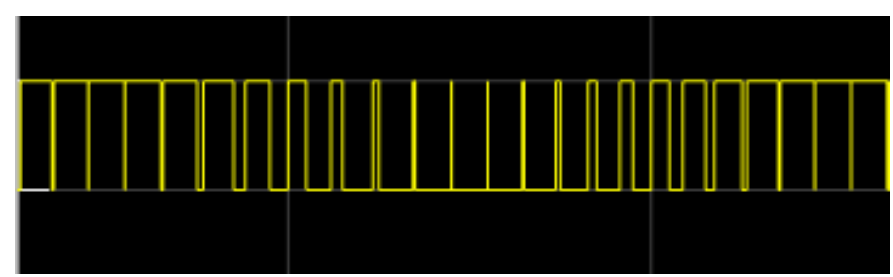

Figure 10 Output 1 of the Sine wave Rectifier

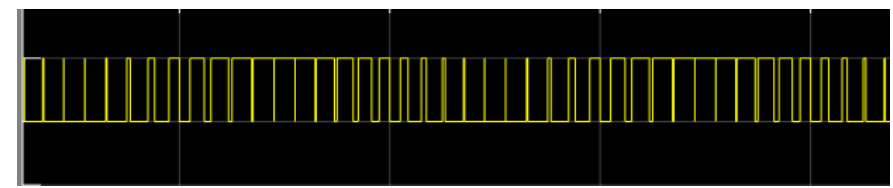

Figure 11 Output 2 of Sinewave Rectifier

The AC yield voltage of a power inverter is regularly managed to be equivalent to the network line voltage, normally 120 or $240 \mathrm{VAC}$ at the conveyance level, notwithstanding when there are changes in the load that the inverter is driving.

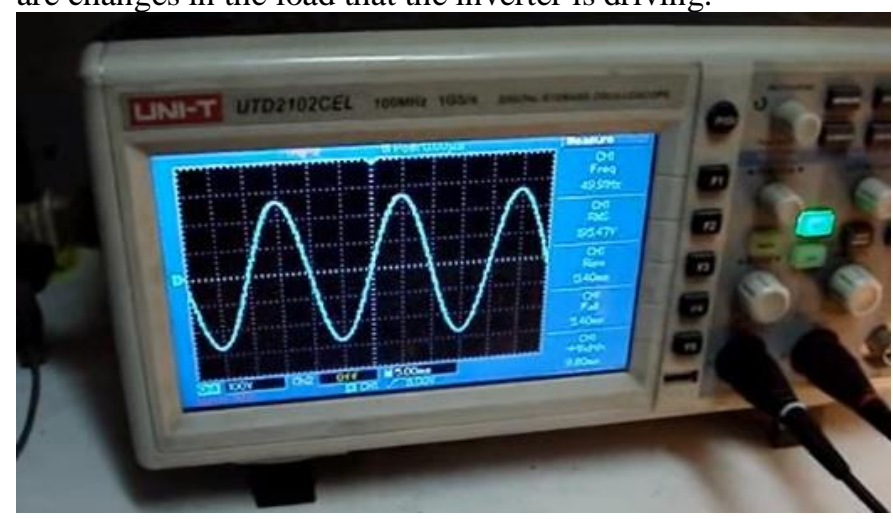

Figure 12 Output Voltages of Inverter

The normal (DC) yield voltage is higher than for half wave, the yield of the full wave rectifier has significantly less ripple than that of the half wave rectifier creating a smoother yield waveform. 
International Journal of Engineering Applied Sciences and Technology, 2021

Vol. 6, Issue 4, ISSN No. 2455-2143, Pages 137-144

Published Online August 2021 in IJEAST (http://www.ijeast.com)

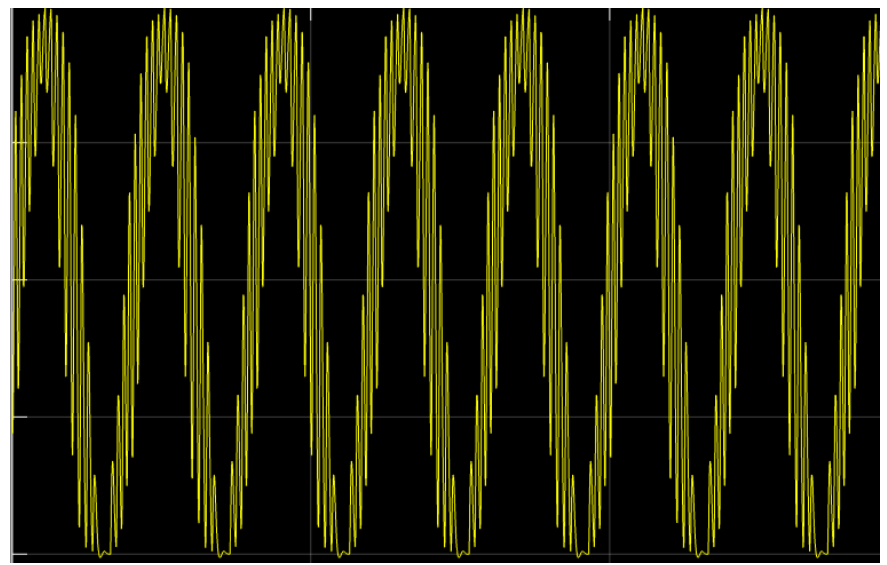

Figure 13 Output Voltages Full Wave

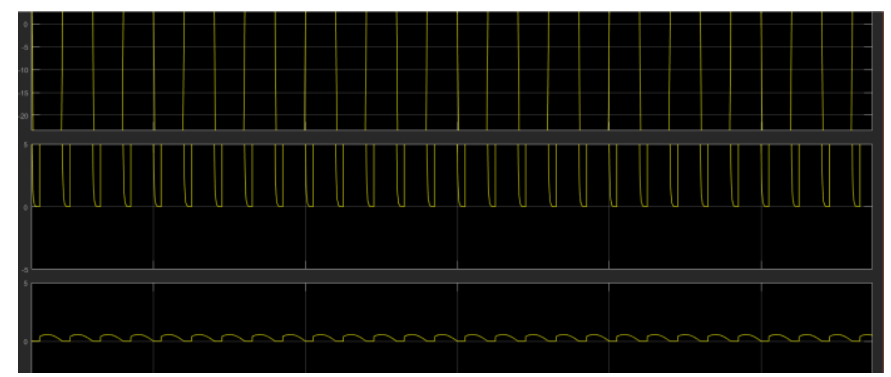

Figure 14 Output of Rectifier

The voltage stability in the presence of STATCOM has been investigated in these results. It has been indicated that voltage stability can be a major problem in microgrid systems with a high penetration of induction DC generator or any other source. On the other hand, the synchronous machine STATCOM generating reactive power or not exchanging reactive power will increase the voltage stability margin.

5.3 Summing up the Results

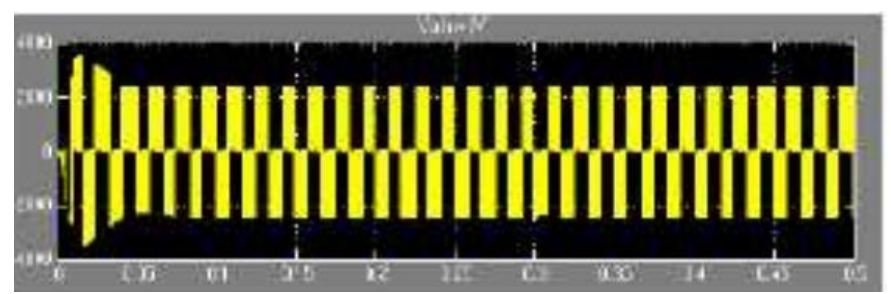

Figure 15 Inverter Waveform

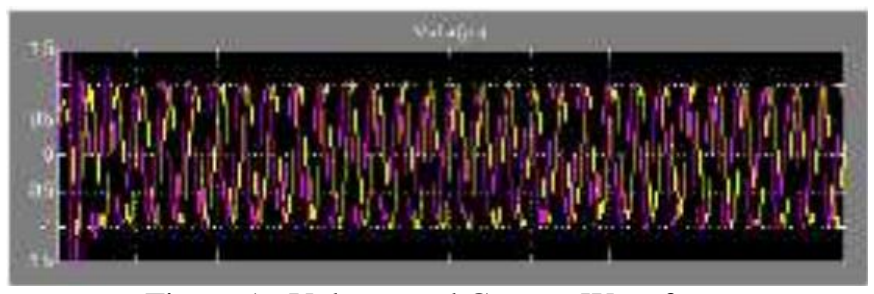

Figure 16 Voltage and Current Waveform

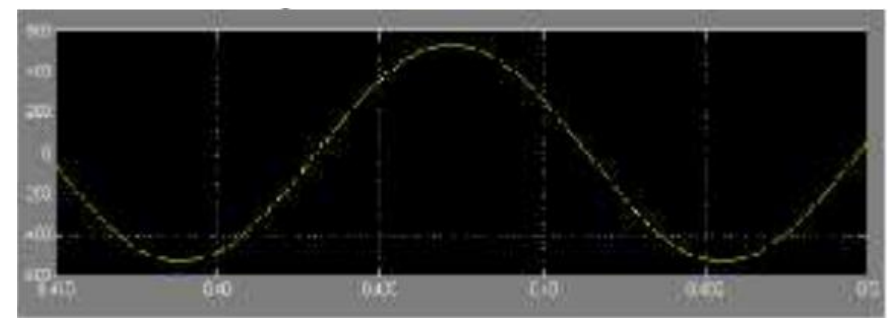

Figure 17 Link Voltage Using STATCOM

In this section of results, this project executed on MATLAB/SIMULINK and results shown. Photovoltaic cell generating the voltage of $\mathrm{AC}$ about 14 to $17 \mathrm{~V}$ in the input which is stabilized by the buck converter to $12 \mathrm{~V}$ as a standard voltage used in this project. Input pulses of saw tooth generator and sinusoidal waves are added as a result to create two different outputs. An adder is added in the output of the two generator having the two outputs. The AC yield voltage of a power inverter is regularly managed to be equivalent to the network line voltage, normally 120 or $240 \mathrm{VAC}$ at the conveyance level, notwithstanding when there are changes in the load that the inverter is driving. The normal (DC) yield voltage is higher than for half wave, the yield of the full wave rectifier has significantly less ripple than that of the half wave rectifier creating a smoother yield waveform. The distribution framework with four feeders has been structured (models shown in previous chapter). At that point to make voltage lists, three stage deficiency has been connected at one of the feeder. At the point, to propel the voltage unstability, STATCOM gadget will be placed in into the circulation framework. STATCOM comprises of controller structure, Voltage Source Converter (VSC) and vitality stockpiling circuit. The wave shape from the degree can be examined to watch either the voltage unstability had shown signs of improvement or not using STATCOM.

\section{CONCLUSION}

Power unstability in the present is a big issue, it can cause different damages to our electricals appliances, and therefore the approach used in this research is for the benefit for these dangerous phenomenon Voltage control single stage STATCOM utilizing distinctive sources, for example, PV, DC generator, battery and WAPDA structured, if there should arise an occurrence of under $9 \mathrm{~V}$ the transfer converter utilized the DC generator as back end source. It is a controller based framework, controller based on voltages changes the source to PV to DC and DC generator to Battery relies on the voltages. Inverter is utilized which take contribution of $12 \mathrm{~V}$ that are controlled by transfer if there should arise an occurrence of PV it is balanced out by buck converter. $1 \mathrm{kVA}$ Transformer at that point sets the voltage to $230 \mathrm{~V}$ single stage It has been utilized STATCOM after transformer to set the voltage at $230 \mathrm{~V}$ Power and Voltage observing framework is utilized to check power and voltages at each point LC load utilized Firstly, It has been used photovoltaic cell which is converting light intensity into 


\section{International Journal of Engineering Applied Sciences and Technology, 2021 \\ Vol. 6, Issue 4, ISSN No. 2455-2143, Pages 137-144 \\ Published Online August 2021 in IJEAST (http://www.ijeast.com)}

AC voltage up to 12 to $17 \mathrm{~V}$, buck converter is used to stabilize these voltages to a 12 volt supply, because intensity of light gives $14 \mathrm{~V}$ as a whole, SPMI is used to create pure sine wave, It has been relay systems which are used as a switch between two sources. In case of PV if there is a darkness the system of relay switched the supply of source to the DC generator, Dc generator converting the mechanical energy into the electrical energy and producing $\mathrm{AC}$ which then converting into DC using rectifiers, DC source can be wind power. Another source using is the battery, when it comes to battery, the relay systems again rectified the current and hen passes to the inverter, if there is not a sufficient power in the battery, the system switches to the WAPDA source, which has $230 \mathrm{~V}$ on inverter. It has been also used power and voltage monitoring system to monitor the supply in microgrid, After that inverter pass AC to transformer, It has been used inverter here because STATCOM uses AC voltage to stabilize Again the AC voltage passes to the STATCOM, synchronization between static condenser create a stability in the voltage after that relay again pass the voltage to the load of LC (Inductor capacitance resonant circuit).

\section{REFERENCE}

[1] N. S. Srivatchan, P. Rangarajan, and S. Rajalakshmi, "Control Scheme for Power Quality Improvement in Islanded Microgrid Operation," Procedia Technol., vol. 21, pp. 212-215, 2015, doi: 10.1016/j.protcy.2015.10.090.

[2] R. Majumder, A. Ghosh, G. Ledwich, and F. Zare, "Enhancing the stability of an autonomous microgrid using DSTATCOM," Int. J. Emerg. Electr. Power Syst., vol. 10, no. 5, pp. 564-569, 2010, doi: 10.2202/1553-779X.2227.

[3] T. Vignesh, K. Dhivya, and R. Chinnaiyan, "International Journal of Advanced Research in Science, Modeling and Simulation of a DSTATCOM for Improvement of Voltage Stability in Microgrid using SPWM Technique ISSN : 2350-0328," vol. 2, no. 11, pp. 991-999, 2015.

[4] A. Sode-Yome, N. Mithulananthan, and K. Y. Lee, "Static voltage stability margin enhancement using STATCOM, TCSC and SSSC," Proc. IEEE Power Eng. Soc. Transm. Distrib. Conf., vol. 2005, no. May 2014, pp. 1-6, 2005, doi: 10.1109/TDC.2005.1547141.

[5] H. Yonezawa et al., "Study of a STATCOM application for voltage stability evaluated by dynamic PV curves and time simulations," 2000 IEEE Power Eng. Soc. Conf. Proc., vol. 2, no. c, pp. 1471-1476, 2000, doi: 10.1109/PESW.2000.850196.

[6] P. Prabhakar and H. Vennila, "Comparison Between Pi , Fuzzy \& Predictive Techniques for Statcom To Improve the Transient Stability of," Int. J. Mech. Eng. Technol., vol. 8, no. 8, pp. 819-829, 2017.

[7] Y. "Vhmad, "VOLAGE STABILITY ENHANCEMENT IN,” 2015.

[8] Y. Zhu, C. Liu, R. Dai, G. Liu, and Y. Xu, "Optimal Battery Energy Storage Placement for Transient Voltage Stability Enhancement.”
[9] H. Zhang, L. Wang, J. Sun, and X. Hu, "Research on the Voltage Stability of Grid Connected Wind Farm Based on STATCOM Technology," vol. 86, no. Eame, pp. 17-20, 2017, doi: 10.2991/eame-17.2017.5.

[10] K. Apornak, "Analyzing the Effect of Using Facts Devices ' STATCOM and SVC' in a Network Including DG Resources in terms of Power Quality " Voltage Sag and Voltage Unbalance,"' vol. 3, no. 6, pp. 95-110, 2016.

[11] H. Miura and G. Wu, "Voltage stabilization of distribution system integrated by renewable power generations by cooperated control of STATCOM and interconnecting microgrids," Int. J. Smart Grid Clean Energy, vol. 3, no. 1, pp. 96-103, 2014, doi: 10.12720/sgce.3.1.96-103.

[12] G. Shahgholian and A. Fattollahi, "Impact of PSS and STATCOM Devices to the Dynamic Performance of a MultiMachine Power System," vol. 7, no. 6, pp. 2113-2117, 2017.

[13] "D-STATCOM for Reactive Power Compensation," vol. 3, no. 3, pp. 111-118, 2015.

[14] T. Nottingham and N. E. User, "Agbedahunsi, Alex Taiwo ( 2013 ) Frequency control for microgrids using enhanced STATCOM and supercapacitor energy storage. PhD thesis , University of Frequency Control for Microgrids using Enhanced STATCOM and Supercapacitor Energy Storage," 2013.

[15] P. Sindhuja and B. Lalitha, "Reactive Power Compensation for Grid Connected Distribution System using Dstatcom for Different Loads," Int. J. Eng. Trends Technol., vol. 40, no. 5, pp. 257-264, 2016, doi: 10.14445/22315381/ijett-v40p242.

[16] S. Rabie and H. Afrakhte, "Optimal determination of island boundaries besides the optimal placement of DSTATCOM devices and DG units," Turkish J. Electr. Eng. Comput. Sci., vol. 25, no. 2, pp. 1508-1521, 2017, doi: 10.3906/elk-1511-225.

[17] G. M. Reddy and T. G. Manohar, "Fuzzy Logic Controller Based STATCOM for Grid Connected Wind Turbine System," vol. 8, no. 2, 2018.

[18] L. F. Montoya, Q. Fu, A. Nasiri, V. Bhavaraju, and D. $\mathrm{Yu}$, "Novel methodology to determine the optimal energy storage location in a microgrid and address power quality and stability," Eat. Corp., no. May, 2014. 